\title{
Neuroeconomics and Confirmation Theory
}

\author{
Christopher Clarke*广
}

Neuroeconomics is a research program founded on the thesis that cognitive and neurobiological data constitute evidence for answering economic questions. I employ confirmation theory in order to reject arguments both for and against neuroeconomics. I also emphasize that some arguments for neuroeconomics will not convince the skeptics because these arguments make a contentious assumption: economics aims for predictions and deep explanations of choices in general. I then argue for neuroeconomics by appealing to a much more restrictive (and thereby skeptic-friendly) characterization of the aims of economics.

1. Neuroeconomics and Evidence. Hypotheses about choices are often key parts of economic models. Models of the consumer, for example, describe how price and income determine the commodities a consumer will choose to consume. But price and income are, in a sense, external to the agent. This illustrates how mainstream economic models restrict themselves to these external factors. At a first approximation they do not explicitly specify how an agent's choice is determined by her internal states, states described either cognitively or neurobiologically.

Contrast this with McClure's (2004) model of decision making, which posits a cognitive process whereby agents compare the available options

Received August 2013; revised September 2013.

*To contact the author, please write to: Department of History and Philosophy of Science, University of Cambridge, Free School Lane, Cambridge CB2 3RH; e-mail: cjc84@cam.ac .uk.

$\dagger \mathrm{I}$ am indebted to Christopher Cowie, Tim Lewens, Don Ross, and two anonymous referees for their helpful comments on this article, and especially to Samir Okasha for his generous comments on an ancestor of this article. I have also profited from more general discussions with Anna Alexandrova, Ken Binmore, David Papineau, and Richard Pettigrew concerning the relationship between psychology and economics. This work was supported by the European Research Council under the European Union's Seventh Framework Programme (FP7/ 2007-2013), ERC grant agreement no. 284123.

Philosophy of Science, 81 (April 2014) pp. 195-215. 0031-8248/2014/8102-0001\$10.00

Copyright 2014 by the Philosophy of Science Association. All rights reserved. 
with each other, a process that takes input from two separate processes upstream. One of these upstream processes is modeled as fast, effortless, evolutionarily ancient, and running in parallel, the other as slow, effortful, evolutionarily recent, and running in series. The evolutionarily ancient process favors impulsive choices and dominates in decisions regarding immediate rewards rather than delayed rewards.

Neuroeconomics is a research program that proposes that economists use such models of decision making, models of how an agent's cognitive and neurobiological states determine her choices. But this proposal is controversial. In the last decade, philosophers, cognitive scientists, neurobiologists, and economists have created a considerable literature on the methodological issues that neuroeconomics raises. The key question under discussion is the relevance of currently available psychological data to economics. And to address this question it will be important to sharpen up the vague talk of "the relevance of psychological data to economics" that one finds in the literature.

First, I propose that we regard as psychological any data that go beyond standard economic "choice data" by narrowing down the specifics of the cognitive or neurobiological mechanisms that underlie choice phenomena. So I will use "psychological data" and "cognitive and neurobiological data" interchangeably. (More on this proposal in secs. 2 and 7.) Second, I propose to read relevance in terms of evidential relevance. For it is uncontroversial that building cognitive or neurobiological models is relevant in that it sometimes provides economists with a creative source of inspiration, just as listening to Bob Dylan, going for a walk, or watching an episode of Lewis might provide inspiration. The central issue - as I see it - is whether the psychological data currently used to build cognitive and neurobiological models constitute evidence that can help answer the questions that mainstream economics ultimately aims to answer.

Thus some economists (Gul and Pesendorfer 2008) and philosophers (Vromen 2010a) claim that cognitive and neurobiological data provide economists with a source of creative inspiration, but that they do not constitute evidence for answering economic questions. ${ }^{1}$ And this reflects some deeply held intuitions of practicing economists (Ross 2012). Indeed it echoes the classic position advocated by Friedman and Savage $(1948,298)$.

1. It is not entirely clear what Gul and Pesendorfer mean by "inspiration." Nor is it always clear how general a claim they intend to make. But for a fairly unambiguous statement of the claim, see Gul and Pesendorfer (2008, 8) and Vromen (2010a, 23). What is clear is that everyone takes Gul and Pesendorfer to be denying that psychological data constitute evidence for or against economic models appropriately construed. See Bernheim (2008, 19), Harrison (2008, 322), Dekel and Lipman (2010, 274), Marchionni and Vromen (2010, 103), Vromen (2010b, 171), and Ross (2011a, 2011b). 
This question should be contrasted with the following one: is building models of cognition or neurobiology an efficient means of answering economic questions? For example, one might concede that psychological data provide economics with evidence for answering economic questions, but of an inefficient sort. For standard economic data remain easier to collect than cognitive and neurobiological data. Furthermore, one might think that when one has enough standard data then any cognitive and neurobiological data become redundant. Alternatively, one might think that recent technological advances have made building models of cognition or neurobiology easier, so doing so is now an efficient means of answering mainstream economic questions. So economists were historically justified in ignoring cognition and neurobiology, but no longer so (Camerer 2008, 60).

This article will argue in favor of neuroeconomics: currently available cognitive and neurobiological data do indeed constitute economic evidence. But I will leave the above question about efficiency unresolved, highlighting it as the locus for fruitful discussion about neuroeconomics in the future.

Sections 2 and 3 will examine two arguments for neuroeconomics that assume an "expansive" characterization of the aims of economics. As a result, I argue, these arguments will not persuade those skeptical of neuroeconomics. Instead, I will propose that one accept a more restrictive characterization of the aims of economics in order to see whether neuroeconomics can still be vindicated on this restrictive characterization. The payoff will be delivered in sections 5 and 7, which will illustrate scenarios in which cognitive and neurobiological data do constitute economic evidence, even on a restrictive characterization, thus vindicating neuroeconomics to even its most thoroughgoing critics. The upshot is that neuroeconomics can be vindicated as an exercise in process tracing (sec. 5) and parameter estimation (sec. 7).

This article also makes a negative point. It will respond in section 4 to an argument from neuroeconomics' opponents, an argument whose conclusion is that a restrictive understanding of economics rules out neuroeconomics. I will employ the apparatus of confirmation theory - absent from the literature so far - to show why this argument fails. I will also use confirmation theory in section 6 to undermine a common argument in favor of neuroeconomics.

2. Restricting the Aims of Economics. The defining/ultimate aim of chess is to checkmate one's opponent, and the means to this end include disrupting one's opponent's pawn structure and capturing her pieces. Thus of any practice one can distinguish the defining/ultimate aims from the merely instrumental means to achieve these aims. So we can distinguish the question of whether it is a defining aim of economics to describe the cognition or neurobiology of decision making from the question of whether 
such descriptions of decision making are of significant instrumental use in pursuit of economics' aims, that is, whether cognitive and neurobiological data constitute evidence for answering economic questions.

This distinction allows one to express with greater precision an argument toward which many contributions to the literature gesture and which takes center stage in Aydinonat $(2010,162-65)$ and Craver and Alexandrova (2008, secs. 4, 5). ${ }^{2}$ Argument: One of the defining aims of mainstream economics is to understand choice phenomena. Economics aims to predict choice events both single and multiple, particular and generic, individual and aggregate, and indeed to provide deep explanations of these events. But psychological data constitute evidence that helps one understand choice phenomena. So psychological data constitute evidence that helps economics pursue its defining aims.

The problem with the above argument is that the first premise is highly controversial. For I think most economists would on reflection deny that the defining aims of mainstream economics include the prediction or deep explanation of choice phenomena in general. ${ }^{3}$ And so a key constituency in the literature is not going to be convinced by the above argument.

It is worth pointing out why one might deny this first premise. When studying decision making, mainstream economists have described how external factors such as price and income determine an agent's choice. And the closest they have come to explicitly modeling the specifics of cognition is when they model how an agent's utility values and beliefs determine her choices. ${ }^{4}$ Any microeconomics textbook or any issue of the American Economic Review will make this clear. And so this talk of utility value and beliefs is the closest economists come to deep explanations of choices or of predicting choices using internal factors. So mainstream economists have not attempted to specify the series of computations performed on internal states that eventually brings about a choice. And this is despite the fact that

2. Rubinstein (2003) adds the rhetorical flourish that the cognitive model he proposes seems to be more consistent with the standard economic data than the as-if model with which he contrasts it. See also Zak (2004), Glimcher, Dorris, and Bayer (2005, 242), Camerer $(2007$, C40; 2008, 45), Bernheim $(2008,15)$, and Gabaix and Laibson (2008, 297), for instance. Note that Aydinonat concedes that psychological data are not evidentially relevant to economic theory or models. He limits his claim to the explanation and prediction of an individual agent's choices.

3. In the neuroeconomics literature, see Bernheim (2008, 3), Dekel and Lipman (2010, 273), and Vromen (2011, sec. 6) for rough agreement on this point and for some discussion. In the economics literature, see Friedman and Savage (1948) and Binmore (2009).

4. At any rate, it is not even clear that economists' talk of utility value and beliefs is to be taken at face value as referring to internal states at all (Friedman and Savage 1948; Binmore 2009). 
it has been perfectly possible to study cognition in the last 50 years using the techniques of cognitive science. The only explanation of this is that mainstream economics does not ultimately aim to specify the details of the cognitive processes of decision making. And the same point applies to the neurobiology of decision making. Economists therefore aim to predict and explain choices at most via a limited class of - mostly external-factors. (See Hausman [2012] for a vigorous exposition of the opposing case.)

At any rate, any such disagreement over the first premise of the above argument will in many ways be a verbal dispute over how restrictively we should apply the label "economics" or, as I am putting it, "mainstream economics." The more important point is, as I have noted, that most economists have a restrictive understanding of economics in mind, an understanding in which economics does not ultimately aim to model cognition or neurobiology. So we can all agree that it is an important question whether neuroeconomics can still be vindicated on this restrictive understanding of economics. Do neurobiological and cognitive data constitute evidence for economics on the supposition that the economics of decision making only aims ultimately to model the influence of external factors on choices? Or, alternatively, do they constitute evidence on the supposition that economics only aims ultimately to model the influence of external factors plus that of utility value and beliefs? In order to answer this question I would ask Alexandrova, Aydinonat, and Craver to grant for this purpose the restrictive understanding of the defining aims of economics.

But one might object as follows: "The debate over neuroeconomics concerns whether economics should aim to model the cognition and neurobiology of decision making. But you insist on a restrictive understanding of economics. In doing so you are simply assuming that it should not model cognition and neurobiology. But why not? Isn't it a laudable aim?" Everyone in the debate accepts that modeling cognition and neurobiology is a laudable aim that ought to be pursued. Indeed in the future this might be an aim that is pursued within university economics departments. All that I am proposing is that we grant a particular definition of mainstream economics at present, a definition that does not include modeling the specifics of cognition and neurobiology as a defining aim. I will have to wait until section 4 to address the concern that to grant this is to automatically rule out neuroeconomics out of hand.

Now to insist upon this restrictive understanding of the defining aims of economics is to highlight a weakness in the manifestos for neuroeconomics. For these manifestos are monopolized by suggestions for how cognitive and neurobiological data might constitute evidence for or against (a) hypotheses about cognitive processes. But the authors rarely bring into focus how cognitive and neurobiological data constitute evidence for or against $(b)$ candidate answers to the questions economics ultimately aims 
to answer. And on a restrictive understanding of economics $a$ and $b$ are very much distinct. Somehow the evidential relevance of cognitive and neurobiological data for $a$ is supposed often to translate into evidential relevance for $b .^{5}$

One of the reasons that this infelicity goes unnoticed I think is because of the ambiguity of the phrase "psychological data." I have been using the phrase to refer just to cognitive and neurobiological data. This I defined in contrast to standard economic choice data, data of the form (external factor, choice). Thus there is a sense in which cognitive and neurobiological data go further than choice data. For they identify - or at least further narrow down - the specifics of the cognitive or neurobiological mechanisms that underlie choice phenomena. But some authors use "psychological data" more nebulously to mean any data collected in the psychology lab, even if the data are just standard economic choice data. Take, for example, data about the choices agents make under lab conditions when playing a prisoner's dilemma or an ultimatum game. And it is easy to see how such data constitute evidence relevant to $b$ economic questions. For these data are just standard economic choice data. Therefore, misled by the ambiguity in "psychological data," one might too hastily draw the conclusion that cognitive and neurobiological data constitute evidence relevant to $b$ economic questions.

So, since my focus is specifically on neuroeconomics rather than on socalled behavioral economics more generally, I will define psychological data as cognitive and neurobiological data. In fact, in focusing on $b$ economic questions rather than $a$ cognitive hypotheses, I will be setting aside old questions about the general methodology of neuroscience. That is, I will be setting aside the long-running controversy over how data from brain-scanning equipment can test cognitive models such as McClure's. Instead, I will be focusing on the wholly new issue raised in the neuroeconomics literature: can cognitive and psychological data answer economic questions?

3. As-If Construals of Economic Models. It is common to talk about testing economic models rather than to talk more broadly about answering economic questions or about the defining aims of economics. So it will be useful to say something about the content of economic models. I take it that the distinctive feature of scientific models is that their content varies for different purposes. For different purposes there are different construals of

5. For example, Camerer, Bhatt, and Hsu $(2007,114)$ say that "creating more realistic assumptions will lead to better predictions." See Zak (2004), Benhabib and Bisin (2008, 321-22), Gabaix and Laibson (2008), Aydinonat (2010, sec. 4), and Dekel and Lipman $(2010,260,264,274)$ for a similar view. 
what the model says. And for the purposes of this article the appropriate construal of an economic model will be a construal that reflects the defining aims of economics. One wants a construal such that to test an economic model is to answer a question that economics ultimately aims to answer.

Now I have proposed that for present purposes we grant the restrictive understanding of the defining aims of economics. So on this understanding we are to construe the model of the consumer, for example, as describing just the relationship between price and income and choice (alternatively: between price, income, utility value, and choice). Of course the model of the consumer might appear to say something very specific about cognitive mechanisms: agents evaluate each of the available bundles of commodities in sequence, and they keep track of the bundle that has most utility value so far in the sequence; the bundle singled out at the end of this process is the bundle the agent will choose. But for present purposes it is appropriate to construe the model of the consumer as not saying anything this specific about cognitive processes. In other words the appropriate construal is some form of as if construal, as economists typically insist (Friedman and Savage 1948). All that the model says is that the relationship between income, price (perhaps utility value) and choice is as if the agent performed the aforementioned computation.

The key question for neuroeconomics then becomes: can cognitive and neurobiological data constitute evidence to test models, such as the model of the consumer, construed in the appropriate as-if manner? This observation has important implications. Consider the expected utility model in economics. One of the founding fathers of neuroeconomics, Colin Camerer, argues that one should construe this model as hypothesizing that agents make decisions via a specific process, which I will label $P$. The hypothesis is that there are "two processes in the brain — one for guessing how likely one is to win and lose, and another for evaluating the hedonic pleasure and pain of winning and losing and another brain region which combines probability and hedonic sensations" (Camerer 2005, 1).

Camerer then claims that we are likely to find psychological data that contradict this cognitive hypothesis. Indeed, were we to find such psychological data the discovery would therefore, he claims, undermine the expected utility model in economics. The structure of Camerer's argument is a simple modus tollens. An economic model entails a specific cognitive hypothesis. One then learns, using cognitive or neurobiological data, that the cognitive hypothesis is false. So one must conclude that the content of the economic model is false also.

Camerer's argument fails for present purposes, however, and for a reason that is now obvious. For the considerations above show that for present purposes we should construe the expected utility model as just describing the relationship between external factors and choice: the relationship is as 
if economic agents compute the expected utility function via specific process $P$ (alternatively: the relationship between external factors, utility value, beliefs and choices is as if ...). Observe that, so construed, the expected utility model does not identify the specific computation that underlies the relationship between these factors. Thus economic models of decision making do not entail specific cognitive hypotheses when they are construed appropriately. So the first premise of Camerer's argument is false.

Despite this easy objection, arguments with Camerer's modus tollens structure are not uncommon in the literature. ${ }^{6}$ So a common way of reasoning in the literature is unsound. Of course to refute this way of reasoning is not to refute the more sophisticated variations upon this way of reasoning. I will wait, however, until section 6 to criticize such variations upon the basic way of reasoning that Camerer exemplifies.

4. Deductivism. I have pointed out that neuroeconomic manifestos and a couple of arguments for neuroeconomics are dialectically weak: these arguments will not convince economists skeptical of neuroeconomics because the arguments implicitly assume an expansive rather than restrictive understanding of the defining aims of economics. Accordingly I have proposed that we grant the restrictive understanding of the aims of economics and then see whether neuroeconomics will be vindicated. Here is an argument that says that it will not be, an argument which I will call the deductivist argument, and which I will go on to criticize.

The deductivist argument: Assume - just to see what follows - the restrictive characterization of the defining aims of economics. So economic models are to be construed as describing the relationship between external environmental factors and choice. But (Deductivism) the test of a hypothesis is in the predictions it makes. More formally: a piece $e$ of one's evidence lends some support to hypothesis $h$ only when one is a logical consequence of the other; similarly $e$ is evidence against $h$ only when one is a logical consequence of the negation of the other. So $e$ is evidence for or against an economic model only when $e$ is a logical consequence of the environment-choice relationship the model posits (or the negation thereof or vice versa). So only data points of the form (choice, external environmental factor) are evidence for or against an economic model. So cognitive or neurobiological data are not evidence for or against economic models. Conclusion $C$ : if one restricts the defining aims of economics then cognitive or neurobiological data are not evidence for or against economic models.

6. See Glimcher et al. (2005, 219, 228), Loewenstein, Rick, and Cohen $(2008,649)$, Spiegler $(2008,520)$, and Frydman et al. (2012), for example. Furthermore, Camerer $(2007$, C39; 2008, 51) and Camerer et al. $(2007,115)$ only make sense on the assumption that economic models entail specific cognitive hypotheses. 
As many commentators note, something like this conditional $C$ is the driving force behind Gul and Pesendorfer's (2008, 7-8) seminal criticism of neuroeconomics. ${ }^{7}$ And the above argument is my best attempt to reconstruct an argument for $C$. Ironically, some enthusiasts for neuroeconomics also endorse the conditional $C$ (Craver and Alexandrova 2008, sec. 3). It is just that the enthusiasts and the critics of neuroeconomics disagree on whether the antecedent of the conditional is true, namely, whether to restrict the aims of economics. And thus they can disagree over the consequent of the conditional, namely, whether cognitive or neurobiological data constitute economic evidence. What I will now do is argue that both sides are too hasty in accepting this conditional. For I will reject the most obvious argument for it, the deductivist argument.

Now an epistemologist's objection to the deductivist argument, I anticipate, may be to argue that deductivism is very similar to hypotheticodeductivism, and that the literature in confirmation theory concerning the "tacking problem" has already shown that hypothetico-deductivism is false (Glymour 1980). So deductivism is false also. And so the deductivist argument fails. (Consider the case in which $e$ confirms $p$. The tacking problem is that hypothetico-deductivism is committed to the following problematic thesis: $e$ confirms $p \wedge q$, no matter what $q$ you choose.)

But this reaction to the deductivist argument is mistaken. Hypotheticodeductivism says that $e$ lends some support to a hypothesis $p(\mathrm{i})$ when $e$ is a logical consequence of $p$ and (ii) only when this is the case. Hypotheticodeductivism is therefore a much bolder thesis than deductivism. This is principally because deductivism only places a necessary condition upon evidential relevance, whereas hypothetico-deductivism also says what is sufficient for it. But it is this sufficient condition, not the necessary condition, that issues in the so-called tacking problem. So deductivism avoids the tacking problem, and our epistemologist's objection to the deductivist argument fails.

My position is to agree with this imaginary epistemologist that the deductivist argument is unsound primarily because deductivism is false. But I will provide an alternative reason to reject deductivism.

I should acknowledge my debt here to Hausman (2008, 140-42), who makes a similar point. My contribution will be to show not just that deductivism fails but to invest time laying out the general epistemological reasons why it fails. Namely, I will show that deductivism cannot handle what I will call confirmational chains. My discussion of this point will bear some structural similarity to the general discussion of confirmation theory in Laudan and Leplin (1991, 461-65), but I take my argument to be an improve-

7. This is noted by Crawford (2008, 249), Harrison (2008, 322), and Vromen (2010b, $172 ; 2011)$. Refer also to Gul and Pesendorfer $(2008,19-22)$ for potential examples. 
ment on theirs. For it avoids the decisive criticisms that Okasha (1997) levels against their argument, criticisms echoed by Psillos $(1999,164)$.

Consider the evidence $e$ that market economies number 1, 2, 3, and 4 experience significant unemployment. And consider the inductive generalization $h$ from the evidence: all market economies experience unemployment. Or rather let $h$ be a conjunction of hypotheses $h=h_{1}, h_{2} \ldots h_{n}$, where, for example, $h_{5}$ says that market economy number 5 experiences unemployment. As deductivism permits, $e$ often lends some support to $h$, and $h$ in turn lends some support to $h_{5}$. But $h_{5}$ neither entails nor is entailed by $e$. Thus deductivism does not permit the support to travel through the chain, so to speak, from $e$ to $h$ to $h_{5}$. That is, it does not permit $e$ to lend any support to $h_{5}$. But one is strongly inclined to think that it is entirely possible for $e$ to lend support to $h_{5}$ in this case. So deductivism is false.

Indeed, one can demonstrate conclusively that this is entirely possible. Imagine further that our agent suspends judgment about $h$ and $h_{5}$ before learning $e$, but after learning $e$ she comes to accept $h$. Whenever a piece of evidence $e$ lends enough support, however, to permit accepting a conjunction $(h$, for example) it lends enough support to permit accepting each of its conjuncts $\left(h_{5}\right.$, for example $) .{ }^{8}$ It follows that $e$ lent some support not just to $h$ but also to $h_{5}$. So it is entirely possible for $e$ to lend support to $h_{5}$ in the present case.

We can run an argument of the same structure, but this time appealing to inference to the best explanation rather than enumerative induction. Take the case in which the "loveliest" explanation for a piece of one's evidence $e$ is a conjunction of hypotheses $h=h_{1}, h_{2} \ldots h_{n}$ (Lipton 1991). (Think of each conjunct as presenting a different part of a very full explanation.) As deductivism permits, $e$ often lends some support to $h$, and $h$ in turn lends some support to $h_{5}$. But $h_{5}$ may well neither entail nor be entailed by $e$. (For example, $h_{5}$ might use theoretical concepts that $e$ does not use.) In this case deductivism does not permit the support to travel through the chain, so to speak, from $e$ to $h$ to $h_{5}$. That is, it does not permit $e$ to lend any support to $h_{5}$. But I have already shown that this is entirely possible in this case. So again deductivism is false.

So the deductivist argument is unsound primarily because deductivism is false, and deductivism is false (for one thing) because it rules out support being passed down confirmational chains. So there is no obvious way of establishing Gul and Pesendorfer's conditional: $(C)$ if one restricts the defining aims of economics then cognitive or neurobiological data are not

8. I do not intend to claim that (1) whenever $e$ lends some support to a conjunction, it lends some support to each of its conjuncts. Nor (2) whenever each of two conjuncts is lent enough support to be accepted, then the conjunction is also. 
evidence for or against economic models. And this should go some distance in assuaging Craver and Alexandrova's concerns that granting the restrictive understanding of the aims of economics will immediately settle the issue in favor of those skeptical of neuroeconomics.

One interesting way of looking at this result is as follows. The restrictive understanding of the defining aims of economics is that these aims involve only factors that are external to the agent rather than internal; where the boundary between internal and external is perhaps something like the boundary between inside the agent's skin and outside her skin. But Ross (2005) has argued that this version of the internal-external distinction is arbitrary: nothing of methodological importance ought to depend upon it. (Indeed he proposes his own more methodologically significant internal-external distinction.) But to argue as I have done that the restrictive understanding does not obviously rule out neuroeconomics is to argue that the "arbitrary" exclusion of factors inside the skin from the defining aims of economics does not obviously lead to their exclusion from economic methodology. And so my argument goes some distance in supporting Ross's claim.

5. Neuroeconomics Vindicated as Process Tracing. I have dismissed two arguments for neuroeconomics as unpersuasive, arguments that rely on an expansive understanding of the defining aims of economics. And I have just shown that assuming a more restrictive understanding of the aims of economics will not obviously undermine neuroeconomics. The project of this section is to assume a restrictive understanding of the aims of economics and show that neuroeconomics can be vindicated.

The basic idea can be simplified as follows. Find a cognitive or neurobiological hypothesis $h$ that entails that this or that economic hypothesis is true or that such and such an economic hypothesis is false. (Note that this is the converse of the problematic idea discussed in sec. 3 that economic models entail that this or that specific cognitive or neurobiological hypothesis is true.) Furthermore the challenge is to find such a hypothesis $h$ that is testable using presently available neurobiological and cognitive techniques. So, put simply, establishing this cognitive or neurobiological hypothesis $h$ would establish some economic hypotheses and undermine others. Thus neuroeconomics is vindicated. I will now illustrate exactly the kind of presently testable cognitive or neurobiological hypothesis I have in mind, namely, the hypotheses involved in process tracing.

Consider the investor-trustee game. One agent (the investor) receives $£ 12$. And she must choose what proportion of this sum to keep and what proportion - if any - to send to another agent (the trustee). The amount sent is then tripled by the experimenter who is overseeing the game. And now the trustee must choose how this tripled amount is to be split between 
herself and the investor. In cases in which the investor invests a large proportion of the $£ 12$ it is common to call the investor's choice "trusting." And in cases in which the trustee acts as if she cares that the split is fair, it is common to call the trustee's preferences "other-regarding."

Suppose that the investor's level of oxytocin in a certain region of her brain is strongly and positively causally relevant to her investing trustingly (Kosfeld et al. 2005). Let us further suppose that exposure to pictures of infants is strongly and positively causally relevant to oxytocin levels in this region of the brain. From this we will often be licensed to accept hypothesis $C$, that exposure to pictures of infants is positively causally relevant to the investor investing trustingly, at least moderately. This is process tracing in action. (Indeed, I think that this process-tracing inference is guaranteed when one reads "strong causal relevance" in an "absolute" rather than an "incremental" sense, but the need for brevity prevents me from developing this undoubtedly controversial claim.)

Contrast all these neurobiological suppositions with the hypothesis motivated by game theory that says investors will — within a small margin of error-choose trusting options to the extent that they have information that the trustee is other regarding. But exposure to infant images presumably does not provide an investor with information as to the trustee's otherregardingness. So the game-theoretic hypothesis requires that exposure to pictures of infants has negligible causal relevance, if any, to trusting investments. And so the game-theoretic hypothesis is false. For it contradicts the alternative hypothesis $C$ that I have just shown to be supported by the neurobiological data via process tracing.

More precisely, to the extent that the neurobiological data ensure that the alternative hypothesis $C$ is probable, the game-theoretic hypothesis is guaranteed to be improbable. After all, Bayesian confirmation theory tells us that whenever a hypothesis contradicts another, it is impossible for the sum of the rational degree of belief in the first and the rational degree of belief in the second to exceed one. By that same token any game-theoretic model whose content entails our improbable game-theoretic hypothesis will be guaranteed to be improbable. For the rational degree of belief in a proposition cannot be higher than the belief in a second proposition that the first entails.

But the above game-theoretic hypothesis, the game-theoretic model, and the alternative hypothesis $C$ describe just what the economics of decision making aims to describe. For they just posit a relationship between external factors (information or exposure to images) and choices. And thus we have a scenario that illustrates how data from currently available neurobiological techniques can constitute evidence that helps economics pursue its defining aims. 
Incidentally, the above may be just the first step of several in the methodology employed by practicing economists. The game-theoretic hypothesis having been rendered improbable, and the alternative hypothesis having been rendered probable, one then has good reason to build a new model that incorporates this alternative hypothesis, that is, to build a model that incorporates infant images as a cause of trusting choices. And the final step will be to test this new model, to firmly reject it or to firmly accept it. It is crucial to see that the argument of this section does not rely on saying anything about this final step, anything about what sort of data can be used to test this new model. For neuroeconomics has already been vindicated within the first step of the above methodology.

I should comment on some peculiarities of the investor-trustee scenario. First, I chose this scenario because it is simple and is one of Colin Camerer's favorite examples. But Camerer describes only half of the investortrustee scenario I described above, namely, the discovery of the link between oxytocin and trusting choices. And he thinks that discovering this link is in itself sufficient to vindicate neuroeconomics. But section 2 shows why this is false given a restrictive understanding of the defining aims of mainstream economics. So one needs something like the infant images part of the scenario in order to have a scenario that vindicates neuroeconomics. It is only in rare cases in the literature that anything like a full process-tracing scenario is spelled out. ${ }^{9}$

Second, and consequently, the other half of the investor-trustee scenario is speculative: the link between infant images and oxytocin is pure speculation on my part for the purposes of illustration. But for our purposes this does not matter. For the infant images experiment is perfectly possible using currently available psychological techniques. So the speculative scenario still illustrates how process tracing can allow data from currently available techniques to constitute evidence against an economic model. Finally, I do not claim that the investor-trustee scenario is an especially inspiring one, for exposure to infant images is not a very interesting factor.

I will conclude by summarizing the key features of process-tracing reasoning. One gets evidence that an external factor (exposure to infant images) is positively causally relevant to a choice factor (trust in the investortrustee game). This is because one gets evidence that the external factor is strongly and positively causally relevant to a cognitive or neurobiological factor (oxytocin levels), which in turn is strongly and positively causally relevant to the choice factor (trust in the investor-trustee game). But economics ultimately aims to describe the above relationship between ex-

9. Glimcher et al. (2005, sec. 5.2) is a notable exception. 
ternal factors and choice. For example, the above discovery may be inconsistent with an economic model that ignores this hitherto-neglected external factor (exposure to infant images). So this discovery is relevant to economics.

6. How Not to Vindicate Neuroeconomics. The last section succeeded in vindicating neuroeconomics while assuming only a restrictive understanding of the defining aims of economics. I will now criticize another argument that tries to achieve exactly the same thing, but fails. This argument in some ways is a more sophisticated version of the argument I attributed to Camerer in section 3.

The argument: take again the hypothesis that expected utilities are literally computed in the brain via the specific process $P$ envisaged in section 3 . Were we to learn that this specific cognitive hypothesis is true, this would lend support to the expected utility model on the appropriate construal (some form of as-if construal). For if the brain of an agent literally computes expected utility via process $P$ then this obviously entails that the agent chooses as if her brain computed expected utility via process $P$. Imagine, however, that we instead discovered that this specific cognitive hypothesis is false. In this case the as-if expected utility model is considerably undermined. For to reject a potential support for a model is to somewhat undermine the model. So we have a scenario in which psychological data constitute evidence against an economic model.

The general idea: an economic model is considerably undermined by learning that a specific cognitive hypothesis is false; a cognitive hypothesis that, had we instead discovered to be true, would have considerably supported the model. This idea seems to me to implicitly underlie the thinking of several major neuroeconomists. ${ }^{10}$ Comparing this way of reasoning with the reasoning I criticized in section 3, one sees that the advantage of the present idea is that it does not construe economic models in an inappropriately expansive rather than restrictive fashion, that is, such that they deductively entail specific cognitive hypotheses.

I will now show, however, that the present idea implicitly requires that we already have considerable reason to believe the following: the economic model holds just in case the specific cognitive hypothesis does. But this is not typically the case at present, construing models in the appropriate as-if manner. For example, we do not at present have considerable reason to believe that the as-if expected utility model holds just in case agents literally compute expected utility in the brain according to specific

10. This is the best way of making sense of Camerer $(2008,372)$, Quartz $(2008,463)$, and Glimcher et al. $(2009,4)$, for example. See also Rustichini $(2005$, sec. 1). 
process $P$. After all - given our present scientific and commonsense knowledge - there are many other computational processes that are plausible as candidate mechanisms for producing expected utility behavior.

In order to make my objection against it, I should point out that there are in fact two readings of the present idea. On the one hand, we might read "the model is considerably undermined" to mean that our confidence in the model should drop to such a level $<\varepsilon_{0}$ that warrants rejecting the model. On the other hand, one might read "the model is considerably undermined" to mean that our confidence in the model should drop by a considerable degree $\alpha$. I will take each reading in turn and argue that in each case the present idea implicitly requires that we already have considerable reason to believe that our economic model holds just in case our specific cognitive hypothesis does.

Applying Bayesian confirmation theory will demonstrate this for the first reading. Now the idea was that a cognitive hypothesis $p$ would lend considerable support to our economic model $M$, were we to learn that the hypothesis is true. On the first reading, this requires that $P(M \mid p)>1-\varepsilon_{1}$, where $1-\varepsilon_{1}$ is the degree of confidence above which one is warranted in accepting $M$ in this context. ${ }^{11}$ And the idea was also that discovering this cognitive hypothesis instead to be false would considerably undermine the economic model $M$. On the first reading, this requires that $P(M \mid \bar{p})<\varepsilon_{0}$, where $\varepsilon_{0}$ is the degree of confidence below which one is warranted in rejecting $M$ in this context. But one can show that these two formal claims entail that $P(M \equiv p)$ is greater than $1-\varepsilon_{0}+\left(\varepsilon_{0}-\varepsilon_{1}\right) P(p)$. But $\varepsilon_{0}$ is low by definition, and $\left(\varepsilon_{0}-\varepsilon_{1}\right) P(p)$ is low by definition irrespective of the value of $P(p)$. So $P(M \equiv p)$ will be close to one. In other words, we already have considerable reason to believe that our economic model holds just in case our specific cognitive hypothesis does.

A Bayesian analysis will also demonstrate my point for the second reading. Again the idea was that a cognitive hypothesis $p$ would lend considerable support to our economic model $M$, were we to learn that the hypothesis is true. On the second reading, this amounts to something like $P(M \mid p)-P(M)=\alpha_{1}$, where $\alpha_{1}$ is considerable - at least a quarter, say. And the idea was also that learning instead that this cognitive hypothesis is false would considerably undermine our economic model $M$. On the second reading, this amounts to $P(M)-P(M \mid \bar{p})=\alpha_{2}$, where $\alpha_{2}$ is considerable - at least a quarter, say. But one can show that these two propositions together entail that

11. In my discussion here I have been making claims such as the following: one should accept a proposition in a context just in case one's degree of belief exceeds threshold $\varepsilon$. Note that my discussion allows the threshold level to vary between contexts and propositions. To impose a fixed threshold would be highly controversial. 


$$
P(M \equiv p)=\frac{2 \alpha_{1} \alpha_{2}+\alpha_{1}}{\alpha_{1}+\alpha_{2}}+P(M) \frac{\alpha_{2}-\alpha_{1}}{\alpha_{1}+\alpha_{2}}
$$

And one can also show that in these circumstances this function is at least as large as $(1 / 2)+\alpha_{1}$ or at least as large as $(1 / 2)+\alpha_{2}$. So $P(M \equiv p)$ will be close to one. In other words we already have considerable reason to believe that our economic model holds just in case our specific cognitive hypothesis does.

So on both readings the present defense of neuroeconomics implicitly requires something that is typically false, namely, that we already have considerable reason to believe that our economic model (on the appropriate asif construal) holds just in case our specific cognitive hypothesis does. So the present defense fails.

7. Loose Ends: Parameter Estimation. That is the main action of the article completed. For the sake of comprehensiveness I will explore another class of scenarios in which psychological data are supposed to constitute evidence that helps economics pursue one of its defining aims. The aim I have in mind here is the aim of estimating the parameters of economic models. I will provide one scenario of parameter estimation that unambiguously succeeds in vindicating neuroeconomics, but I will first describe two scenarios of parameter estimation whose significance is less clear.

Scenario 1. Folk tend not to spend all their savings in their old age when death is approaching. One can make sense of such behavior by supposing that these folk prefer to bequeath something to their children. Or one can make sense of such behavior by supposing that these folk prefer not to risk a miserable standard of living, in the case in which they live longer than expected. Are they motivated by bequests or precaution? In answer to this question one might suppose that an agent's lifelong planconcerning when to spend and when to save-optimizes a utility function with a parameter $\theta$ where $\theta$ denotes the extent to which that agent values making bequests to their children more than guaranteeing themselves a good standard of living.

One way of attempting to estimate an agent's $\theta$ is to ask her to introspect and report what spending-saving plan she is using. That is, experimenters might ask her to report how much she would choose to spend and to save were various contingencies to arise. Let us imagine that these introspectively reported hypothetical choices are consistent with this agent maximizing a utility function for which $\theta$ takes value 0.3 but not for which $\theta$ takes value 0.6 . So these introspective hypothetical choices suggest that $\theta$ is 0.3 for our agent. Let us call this introspection-based estimate $\theta^{*}$. 
Now here is the most important point: imagine that one discovers that $\theta^{*}$ is a good estimator of $\theta$. (I imagine one might commission an expensive study employing a small sample of pensioners from our population. One ferrets out their detailed spending and saving records over a long time in order to measure $\theta$. One then observes that this closely matches $\theta^{*}$, the estimate based on introspective hypothetical choices. One might then extrapolate from this that $\theta^{*}$ is a good estimator of $\theta$ for all agents in our population.) And so one might estimate the distribution of $\theta$ in our population by first discovering the distribution of $\theta^{*}$ in our population. (To do this I imagine one might commission a cheap survey. One asks a mediumsized sample of students, workers, and pensioners to answer a spendingsaving questionnaire.)

But the distribution of this parameter $\theta$ in the population is the kind of question that mainstream applied economics aims to answer. For this parameter partially characterizes what options a population of agents will each choose under different external constraints, for example, under different tax policy interventions. So we have a scenario in which introspective data constitute evidence for answering an economic question.

But do these introspective data constitute psychological data? For sure, no introspective data are standard economic data. So these data meet the first of my two necessary conditions for being psychological data (sec. 1). But these introspective data do not seem to identify-or at least narrow down more than standard economic data do - the cognitive or neurobiological mechanisms that produce choice phenomena. All they do is purport to tell us about how an agent would choose under various contingencies. So they seem to fail my second necessary condition for being psychological data. What this illustrates, I think, is that the evaluation of neuroeconomics in part depends on how one understands psychological data, and the literature has left the notion very vague. So the significance of this scenario is unclear.

Scenario 2. Schotter (2008, 73-79) presents a model of decision making in which agents interact with other agents. First, agents are modeled as having probabilistic beliefs about what action the other agents will engage in. Second, agents choose the action that maximizes expected utility in light of their beliefs. Third, Schotter makes no further assumptions about agents' beliefs; for instance, he does not assume that these beliefs are rational, as standard game theory would assume. Now Schotter estimates an agent's beliefs by asking the agent to introspect and report her beliefswhen she is suitably incentivized to tell the truth (Nyarko and Schotter 2002). (Note that these data have a better claim to be counted as psychological data because what is being introspectively reported is the agent's beliefs, not hypothetical choices as in scenario 1.) And plugging these es- 
timates of the belief parameters into Schotter's model, it turns out, leads to an economic model that is very good at predicting the agent's own choices.

And this, of course, will hold when we construe Schotter's model in an extreme as-if manner as merely describing the choices agents will make in this interactive scenario. That is, as not describing anything to do with any internal states, not to mention cognition. It follows that there is a correlation, so to speak, between the belief parameters in this as-if economic model and estimates of these parameters based on individuals' introspective reports. Thus we have a scenario in which (putatively) psychological data provide evidence to parameterize an economic model.

The more extreme critics of neuroeconomics might doubt, however, that mainstream economics is ultimately interested in estimating the parameters in models such as Schotter's. For these parameters describe highly transient features of agents, features that vary across short periods of time within any given agent, rather than the stable ones that one finds in scenario 1 . And these critics may deny that economics ultimately aims to measure such highly transient parameters. (Of course, this is not to detract from the importance of Schotter's work for our understanding of the psychology of decision making.) So Schotter's work may not provide the maximally compelling exemplar available of the pursuit of mainstream economic aims via cognitive science. And it is to the most compelling sort of exemplars that I now turn.

Scenario 3. Consider an economic model of decision making under uncertainty that describes an agent's choices as optimizing a utility function that is not the expected utility function but rather something more complicated. The details are not important. All that matters it that this function contains a so-called ambiguity aversion parameter. Suppose one establishes that this ambiguity aversion parameter covaries (across individual agents) with a certain neurobiological feature. For example, it covaries with a pattern of activity in the agents' orbitofrontal cortices during certain choice tasks, as Hsu et al. (2005) demonstrated. As Camerer (2008, 49) suggests, it follows that if one measures the distribution of this neurobiological feature in the population, one can estimate the distribution of ambiguity aversion in that population. Thus we have a scenario in which currently available cognitive or neurobiological data constitute evidence relevant to answering a question that mainstream economics aims to answer.

Let us contrast the logical structure of the present parameter-estimation scenarios with the process-tracing scenarios of section 5 . In the parameterestimation scenarios one takes it for granted that the economic model under examination is a good one. And one discovers that a psychologically measured $\theta^{*}$ is a good estimator of a parameter $\theta$ in that economic model. This fact allows us to estimate the distribution of $\theta$ in the population by first 
estimating the distribution of $\theta^{*}$. In the process-tracing scenarios, in contrast, one does not assume from the outset that the economic model is good. For example, in many process-tracing scenarios psychological data undermine our economic model. And they do so by pointing out that the model has ignored a crucial external cause of choice behavior. So the processtracing scenarios embody a bolder way in which psychological data are relevant to economics than the more modest parameter-estimation scenarios.

I should emphasize that I intend my distinction between parameter estimation and process tracing to shed light on the logic of confirmation underlying neuroeconomics. In actual practice neuroeconomic reasoning will typically use both sorts of reasoning in tandem. For example, one might first use something similar to process tracing to establish that a neurobiological variable is (likely to be) a good estimator of a parameter in an economic model. One might then directly confirm that this is the case and then use this neurobiological variable for the purposes of parameter estimation. ${ }^{12}$

8. Conclusion. Sections 2, 3, and 6 rejected three arguments for neuroeconomics; the first two appealed to an expansive understanding of the aims of economics; the third appealed only to a restrictive understanding. And it was the use of Bayesian confirmation theory that exposed the flaw in the argument considered in section 6. Similarly section 4 engaged with general confirmation theoretical issues to reject an argument against neuroeconomics. This argument relied on deductivism, a necessary condition on when some evidence will support a hypothesis. I showed that deductivism precludes confirmation "traveling down chains" in cases of enumerative induction and inference to the best explanation.

These are the negative claims of this article. More positively, section 5 (and in a more qualified way sec. 7) illustrated how currently available cognitive and neurobiological data can constitute evidence for answering questions that mainstream economics ultimately aims to answer: supporting and undermining economic models via process tracing (sec. 5) and estimating the parameters of already established models (sec. 7).

These arguments have the advantage over the arguments considered in sections 2 and 3, in that they do not problematically assume that economics ultimately aims to predict and deeply explain choices in general. (Instead, they take it that economics ultimately aims to describe only how certain factors determine choice and to explain choices only using these factors. These factors are external factors, with the possible exception of utility value and beliefs.) The fact that these arguments do not make this problematic assumption is a good thing, because this assumption is rejected by those econ-

12. Don Ross, private communication. 
omists who are skeptical of neuroeconomics (sec. 2). So the arguments of sections 5 and 7 will likely persuade these skeptics, unlike the arguments of sections 2 and 3 .

\section{REFERENCES}

Aydinonat, N. Emrah. 2010. "Neuroeconomics: More than Inspiration, Less than Revolution." Journal of Economic Methodology 17:159-69.

Benhabib, Jess, and Alberto Bisin. 2008. "Choice Theory and Process: Theory Ahead of Measurement." In The Foundations of Positive and Normative Economics: A Handbook, ed. Andrew Caplin and Andrew Schotter, 320-36. Oxford: Oxford University Press.

Bernheim, B. Douglas. 2008. "Neuro-economics: A Sober (but Hopeful) Appraisal." Technical Report, NBER Working Paper Series. Also later revised as "On the Potential of Neuroeconomics: A Critical (but Hopeful) Appraisal.” American Economic Journal: Microeconomics $1: 1-41$.

Binmore, Ken. 2009. Rational Decisions. Princeton, NJ: Princeton University Press.

Camerer, Colin F. 2005. "What Is Neuroeconomics?" Unpublished manuscript. Cited in Gul and Pesendorfer 2008, 21; and Vromen 2010a, 34.

. 2007. "Neuroeconomics: Using Neuroscience to Make Economic Predictions." Economic Journal 117: C26-C42.

- 2008. "The Case for Mindful Economics." In The Foundations of Positive and Normative Economics: A Handbook, ed. Andrew Caplin and Andrew Schotter, 43-69. Oxford: Oxford University Press.

Camerer, Colin F., Meghana Bhatt, and Ming Hsu. 2007. "Neuroeconomics: Illustrated by the Study of Ambiguity Aversion." In Economics and Psychology: A Promising New CrossDisciplinary Field, ed. Bruno S. Frey and Alois Stutzer, 113-51. Cambridge, MA: MIT Press.

Craver, Carl, and Anna Alexandrova. 2008. "No Revolution Necessary: Neural Mechanisms for Economics." Economics and Philosophy 24:381-406.

Crawford, Vincent P. 2008. "Look-Ups as the Window of the Strategic Soul." In The Foundations of Positive and Normative Economics: A Handbook, ed. Andrew Caplin and Andrew Schotter, 249-79. Oxford: Oxford University Press.

Dekel, Eddie, and Barton L. Lipman. 2010. "How (Not) to Do Decision Theory." Annual Review of Economics 2:257-82.

Friedman, Milton, and L. J. Savage. 1948. "The Utility Analysis of Choices Involving Risk." Journal of Political Economy 56:279-304.

Frydman, Cary, Nicholas Barberis, Colin Camerer, Peter Bossaerts, and Antonio Rangel. 2012. "Using Neural Data to Test a Theory of Investor Behavior: An Application to Realization Utility.” Technical Report, NBER Working Paper no. 18562, National Bureau of Economic Research, Cambridge, MA.

Gabaix, Xavier, and David Laibson. 2008. "The Seven Properties of Good Models." In The Foundations of Positive and Normative Economics: A Handbook, ed. Andrew Caplin and Andrew Schotter, 292-319. Oxford: Oxford University Press.

Glimcher, Paul W., Colin F. Camerer, Ernst Fehr, and Russell A. Poldrack. 2009. "Introduction: A Brief History of Neuroeconomics." In Neuroeconomics: Decision Making and the Brain, ed. Paul W. Glimcher, Colin F. Camerer, Ernst Fehr, and Russell A. Poldrack, 1-12. London: Elsevier/Academic Press.

Glimcher, Paul W., Michael C. Dorris, and Hannah M. Bayer. 2005. "Physiological Utility Theory and the Neuroeconomics of Choice." Games and Economic Behavior 52:213-56.

Glymour, Clark. 1980. "Hypothetico-Deductivism Is Hopeless." Philosophy of Science 47:32225.

Gul, Faruk, and Wolfgang Pesendorfer. 2008. "The Case for Mindless Economics." In The Foundations of Positive and Normative Economics: A Handbook, ed. Andrew Caplin and Andrew Schotter, 3-39. Oxford: Oxford University Press. 
Harrison, Glenn W. 2008. "Neuroeconomics: A Critical Reconsideration." Economics and Philosophy 24:303-44.

Hausman, Daniel M. 2008. "Mindful or Mindless Economics: A Methodological Evaluation.” In The Foundations of Positive and Normative Economics: A Handbook, ed. Andrew Caplin and Andrew Schotter, 125-53. Oxford: Oxford University Press.

. 2012. Preference, Value, Choice and Welfare. Cambridge: Cambridge University Press.

Hsu, Ming, Meghana Bhatt, Daniel Tranel, Ralph Adolphs, and Colin F. Camerer. 2005. "Neural Systems Responding to Degrees of Uncertainty in Human Decision-Making." Science 310:1680-83.

Kosfeld, Michael, Markus Heinrichs, Paul J. Zak, Urs Fischbacher, and Ernst Fehr. 2005. "Oxytocin Increases Trust in Humans." Nature 435:673-76.

Laudan, Larry, and Jarrett Leplin. 1991. "Empirical Equivalence and Underdetermination.” Journal of Philosophy 88:449-72.

Lipton, Peter. 1991. Inference to the Best Explanation. London: Routledge.

Loewenstein, George, Scott Rick, and Jonathan D. Cohen. 2008. "Neuroeconomics." Annual Review of Psychology 59:647-72.

Marchionni, Caterina, and Jack Vromen. 2010. "Neuroeconomics: Hype or Hope?” Journal of Economic Methodology 17:103-6.

McClure, Samuel M. 2004. "Separate Neural Systems Value Immediate and Delayed Reward." Science 306:503-7.

Nyarko, Yaw, and Andrew Schotter. 2002. “An Experimental Study of Belief Learning Using Elicited Beliefs." Econometrica 70:971-1005.

Okasha, Samir. 1997. "Laudan and Leplin on Empirical Equivalence." British Journal for the Philosophy of Science 48:251-56.

Psillos, Stathis. 1999. Scientific Realism: How Science Tracks Truth. London: Routledge.

Quartz, Steven R. 2008. "From Cognitive Science to Cognitive Neuroscience to Neuroeconomics." Economics and Philosophy 24:459-71.

Ross, Don. 2005. Economic Theory and Cognitive Science. Cambridge, MA: Bradford/MIT Press. - 2011a. "Cognitive Variables and Parameters in Economic Models." In Grounding Social Sciences in Cognitive Science, ed. R. Sun, 287-314. Cambridge, MA: MIT Press.

- 2011b. "Neuroeconomics and Economic Methodology." In The Elgar Companion to Recent Economic Methodology, ed. John B. Davis and D. Wade Hands, 61-93. Cheltenham: Elgar.

- 2012. "Mäki's Realism and the Scope of Economics." In Economics for Real: Uskali Mäki and the Place of Truth in Economics, ed. Aki Lehtinen, Jaakko Kuorikoski, and Petri Ylikoski, 181-202. Abingdon: Routledge.

Rubinstein, Ariel. 2003. "“Economics and Psychology'? The Case of Hyperbolic Discounting.” International Economic Review 44:1207-16.

Rustichini, Aldo. 2005. "Neuroeconomics: Present and Future." Games and Economic Behavior 52:201-12.

Schotter, Andrew. 2008. "What's So Informative about Choice?" In The Foundations of Positive and Normative Economics: A Handbook, ed. Andrew Caplin and Andrew Schotter, chap. 3, 70-94. Oxford: Oxford University Press.

Spiegler, Ran. 2008. "Comments on the Potential Significance of Neuroeconomics for Economic Theory." Economics and Philosophy 24:515-21.

Vromen, Jack. 2010a. "On the Surprising Finding That Expected Utility Is Literally Computed in the Brain." Journal of Economic Methodology 17:17-36.

- 2010b. "Where Economics and Neuroscience Might Meet." Journal of Economic Methodology 17:171-83.

. 2011. "Neuroeconomics: Two Camps Gradually Converging; What Can Economics Gain from It?" International Review of Economics 58:267-85.

Zak, Paul J. 2004. "Neuroeconomics.” Philosophical Transactions of the Royal Society of London 359:1737-48. 